\title{
Structural changes of selected materials for glass industry after thermal loading
}

\author{
Františka Pešlová ${ }^{*}, 1$, Mariana Janeková ${ }^{1}$, Stanislav Krum $^{2}$ \\ ${ }^{1}$ University of Alexander Dubček in Trenčín, Faculty of Industrial Technologies, I. Krasku 1809/34, \\ 02001 Púchov, Slovakia \\ ${ }^{2}$ Czech Technical University in Prague, Department of Materials Engineering, Karlovo nam. 13, \\ 12132 Prague 2, Czech Republic
}

\begin{abstract}
The presented paper is focused on study and investigation of structural changes in relation to the selected materials which are exposed to the thermal loading. The given work is connected with closer investigation of such material as Dominial ZF 2 which is commonly used for production of steel moulds and components in the glass industry. Moreover, the given work is also devoted to the investigation of materials which are commercially called Toolox 33 and Toolox 44 because these materials were proposed by firm to be used as substitutive materials of Dominial ZF 2. Both of the mentioned and investigated materials have not been used in glass industry yet. Experimental procedures were proposed on the basis of the fact that the investigated materials are exposed to thermal as well as mechanical loading and they are in direct interaction with hot molten glass. After simulated thermal loading, the investigated materials were exposed to the static tensile test and by this way, it was possible to obtain samples with fracture surfaces and these fracture surfaces were evaluated in terms of characteristic features relating to rupture. On the basis of the obtained results and knowledge from experimental procedures, Toolox 33 and Toolox 44 are not recommended to be used for production of steel moulds and components for glass products.
\end{abstract}

Keywords: thermal loading, glass moulds, fracture, material fatigue, $\mathrm{Cr}-\mathrm{Ni}$ steel, stress-strain states, degradation

\section{Introduction}

Machine production of glass products consists of pouring the molten glass into metallic molds, where it is cooled and solidifies in order to obtain the desired glass shape. During the operation, undesired processes may occur in metallic material. This is reflected in the overall life-time of the glass molds and consequently in the quality of finished glass products.

In glass manufacturing plants, the high-alloyed chromium-nickel austenitic steel with high declared heat resistance, high and low temperature corrosion resistance under the designation DOMINIAL ZF2 is predominantly used. From an economic point of view, the

\footnotetext{
${ }^{*}$ Corresponding author: frantiskap@seznam.cz
}

Reviewers: Eva Tillová, Ján Vavro 
company is considering replacing this material with a cheaper steel grade. Toolox 33 and Toolox 44 martensitic steels with similar declared material properties as DOMINIAL ZF2 were selected as potential replacements.

The purpose of this work was to investigate the behavior of materials subjected to critical heat load until the moment of the first crack initiation [1 - 4]. Simulation of heat load cycles was performed using a custom made device. Based on the formation of the fracture surface and the character of the crack propagation, the resistance against the failure by cyclic temperature changes of all the studied materials was compared.

For purpose of the simulated high temperature testing, test specimens were produced in a way that allowed observation of the effects of these changes after the cyclic loading. The samples were rapidly heated to app. $800^{\circ} \mathrm{C}$ and then cooled down (in app. 5 seconds). During the heat load breaks, a visual check between the individual cycles was conducted to identify the initiation of the failure. The fracture surfaces prepared by the finishing failure using a static tensile test machine were compared fractographically. Evaluation was carried out on all materials after the identical number of cycles (50 cycles).

\section{Characteristics of the evaluated materials}

Toolox 33 may be described as a quenched and subsequently tempered tool steel. It is made with low residual stress, resulting in very good dimensional stability. This material does not require further heat treatment and has excellent workability. It is weldable and can be used with a polished surface. The steel is one of the low alloyed materials (it can be tempered at approx. $600{ }^{\circ} \mathrm{C}$ ). The standard does not recommend this steel to be exposed to temperature higher than $590{ }^{\circ} \mathrm{C}$, where the declared properties are not guaranteed anymore [5].

Table 1. Chemical composition of the selected materials

\begin{tabular}{|c|c|c|c|c|c|c|c|c|c|c|}
\hline \multirow{2}{*}{ Material } & \multicolumn{7}{|c|}{ Chemical composition [wgt.\%] } \\
\cline { 2 - 11 } & $\mathbf{C}$ & $\mathbf{S i}$ & $\mathbf{M n}$ & $\mathbf{C r}$ & $\mathbf{N i}$ & $\mathbf{M o}$ & $\mathbf{P}$ & $\mathbf{S}$ & $\mathbf{A l}$ & $\mathbf{V}$ \\
\hline $\begin{array}{c}\text { Dominial ZF 2 - } \\
\text { as delivered }\end{array}$ & 0,12 & 2 & 0,9 & 25 & 20 & $*$ & $*$ & $*$ & $*$ & $*$ \\
\hline $\begin{array}{c}\text { Dominial ZF 2 } \\
\text { Chemical analysis- } \\
\text { CTU }\end{array}$ & $*$ & 1.31 & 1.06 & 28.61 & 15.36 & $*$ & $*$ & 0.10 & 0.26 & $*$ \\
\hline $\begin{array}{c}\text { Toolox 33 - } \\
\text { as delivered }\end{array}$ & 0.25 & 0.60 & 0.90 & 1.20 & 0.70 & 0.40 & 0.010 & 0.004 & $*$ & 0.125 \\
\hline $\begin{array}{c}\text { Toolox 33 - } \\
\text { Chemical analysis- } \\
\text { CTU }\end{array}$ & $*$ & 0.92 & 0.84 & 1.47 & $*$ & 0.71 & $*$ & $*$ & 0.15 & 0.17 \\
\hline $\begin{array}{c}\text { Toolox 44 - } \\
\text { as delivered }\end{array}$ & 0.31 & 0.60 & 0.90 & 1.35 & 0.70 & 0.80 & 0.010 & 0.004 & & 0.145 \\
\hline $\begin{array}{c}\text { Toolox 44 } \\
\text { Chemical analysis- } \\
\text { CTU }\end{array}$ & $*$ & 1.01 & 0.79 & 1.44 & $*$ & $*$ & $*$ & 0.24 & 0.19 & 0.20 \\
\hline
\end{tabular}

Toolox 44 may be considered identical to Toolox 33 when based on several properties. It is also a quenched and subsequently tempered tool steel with excellent dimensional stability, workability and excellent polishing capability. The working conditions are similar, which means that it should not be exposed to temperatures higher than $590{ }^{\circ} \mathrm{C}$ for a longer time periods. Unlike Toolox 33, it has a different chemical composition (Table 1) and is shows better toughness. These materials should be homogeneous with high metallurgical 
purity and good thermal conductivity. They are used for machining, welding and various surface treatments [6].

\section{Evaluation of microstructure changes}

By the evaluating the micropurity of the specifically delivered steels (Toolox 33 and Toolox 44), relatively large amounts of carbonitrides and complexes based on oxycarbonitrides and relatively high content of sulfide inclusions were found in the structure. In cases of all the investigated materials, (incuding Dominial ZF2) the local occurrence of oxide phases was observed.

The microscopic examination of the delivered materials showed that both proposed steels had a structure consisting of lower bainite, respectively of sorbite with local occurrence of martensitic needles and residual austenite (Fig. 1, Fig. 4). The microstructure of the Dominial ZF2 steel is austenitic with the occurrence of fine carbides along the grain boundaries (Fig. 7).

Samples were made from all of these materials for a simulated cyclic heat load test which was followed by a finishing failure using the instrument used for static tensile testing. The heat load cycling of individual materials took place until the first crack initiation occurred. The cyclical heating of Toolox 33 was finished after app. 80 cycles, Toolox 44 after about 50 cycles, and DOMINIAL ZF2 after about 90 cycles or more (when the first initiation of the failure occurred). Attention was paid to the failure and fracture surfaces of all materials after the same number of cycles (50 cycles) (Fig. 3, 6 and 9).

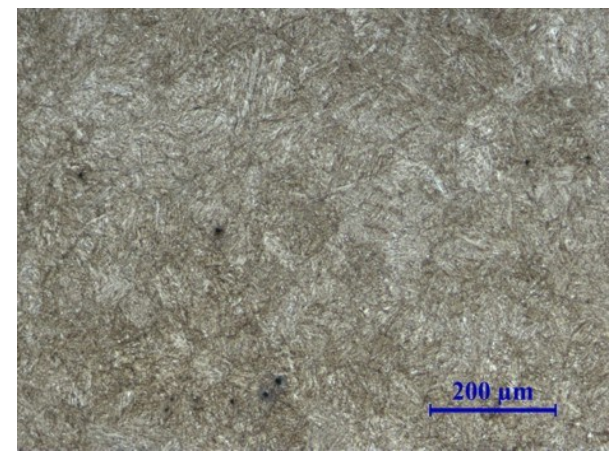

Overview

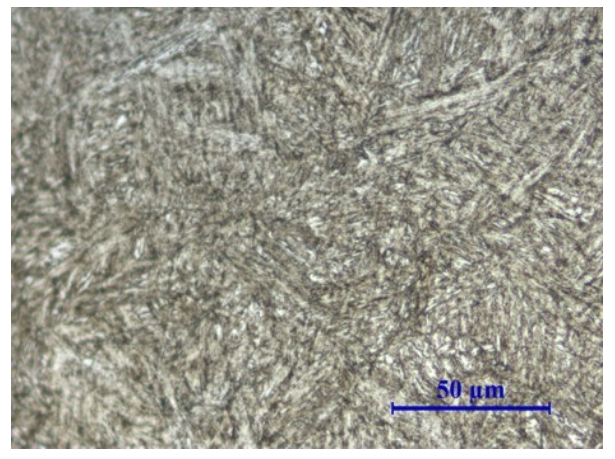

Detail

Fig. 1. Microstructure of the as delivered Toolox 33 material - uncycled

On metallographically prepared sections (Fig. 2) of the area under the fracture surface (after the heat load cycles), structural changes that characterized the fatigue process around the crack were observed. In this area, there occurred strain-strass state, which subsequently resulted in a failure. The fracture surface shows the defined locations in the structure, which are typical for the coexistence of individual phases with different ductile and strength characteristics (Fig. 3). These areas support the local concentration of microdeformation processes leading at different sites to cohesion failure (the red arrow indicates the site of initiation and the occurrence of secondary cracks). 


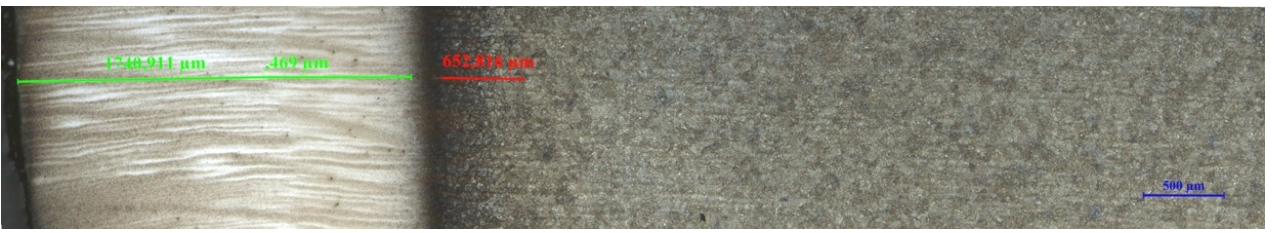

Fig. 2. Microstructure in the proximity of the failure - Toolox 33 - after 50 cycles

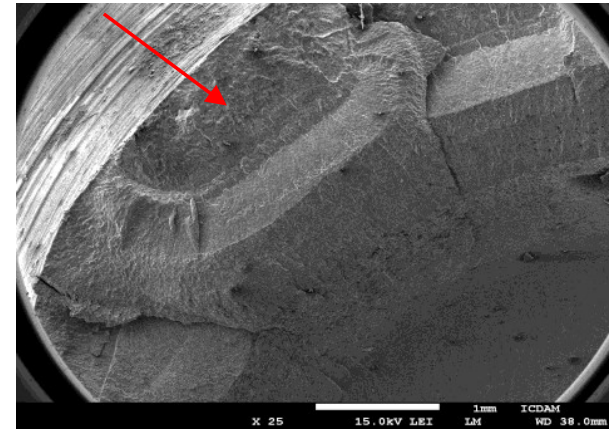

Overview

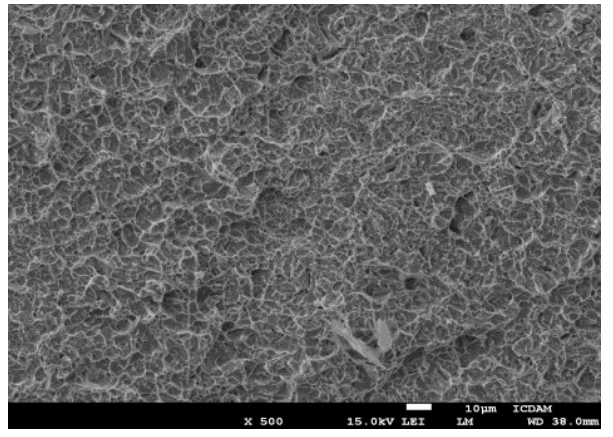

Detail

Fig. 3. Fracture surface of Toolox 33 after 50 cycles

Toolox 44 has a similar microstructure (Fig.4) as Toolox 33 including the occurrence of inclusions formed due to chemical heterogeneity of the material.

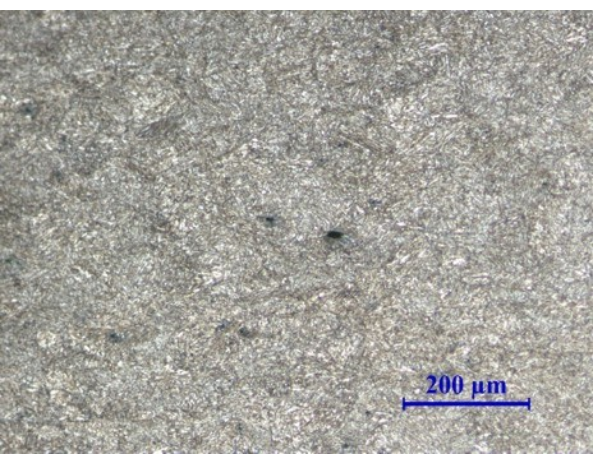

Overview

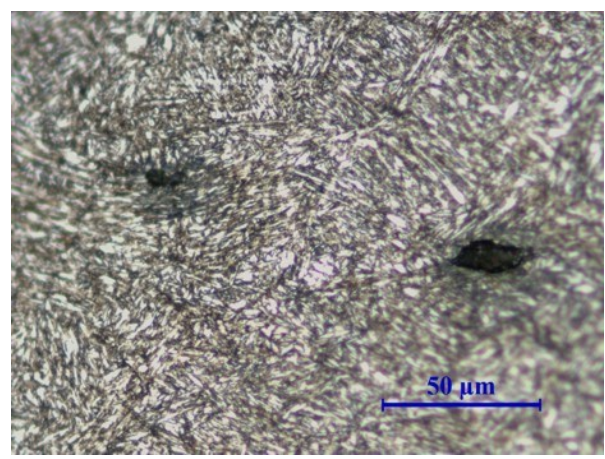

Detail

Fig. 4. Microstructure of the as delivered Toolox 44 material - uncycled

Even in this case, there is a structurally changed zone after the heat load cycles, where exist high stress - strain states (Fig. 5) as in the previous material. The scale of this area will be dependent on character of the as delivered steel.

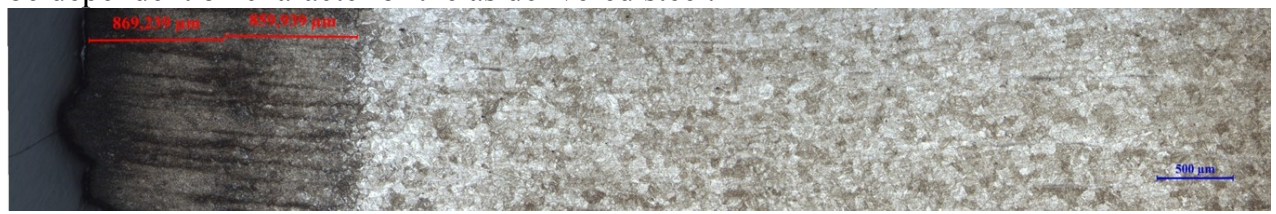

Fig. 5. Microstructure under the fracture surface - Toolox 44 - after 50 cycles 
In the given case, it is a failure of the mixed nature, where ductile and fragile locations alternate in the fracture surface depending on the character of phases present in the structure (Fig. 6). The arrow point at the initiation sites of the failures.

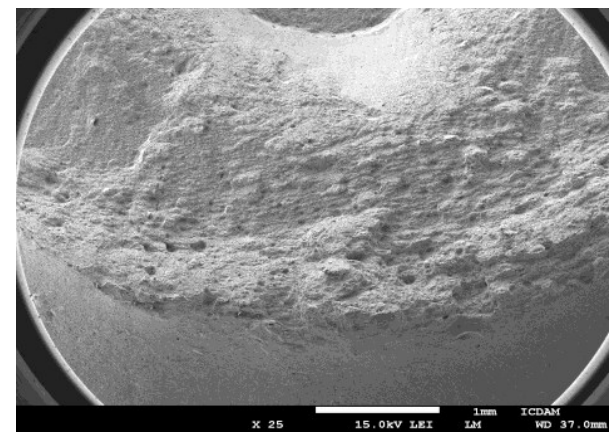

Overview

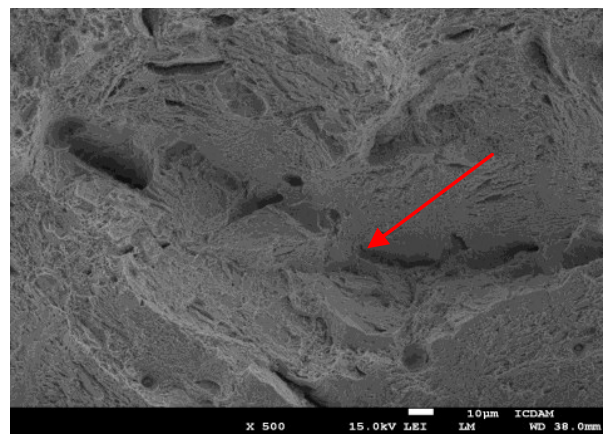

Detail

Fig. 6. Fracture surface - Toolox 44, after 50 cycles

Dominial ZF2 steel is heterogeneous depending on size of austenitic grains (Fig. 7), which react to changes of deformation effects (after 50 heat load cycles) in different ways. There occurs a texture, which cease to exist in proximity of the fracture surface (Fig. 8).

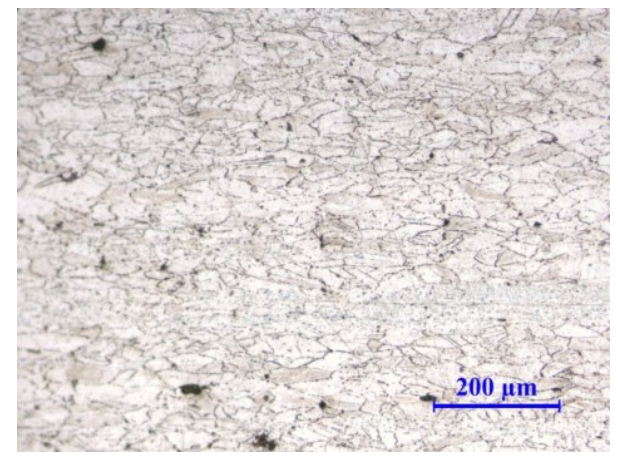

Overview

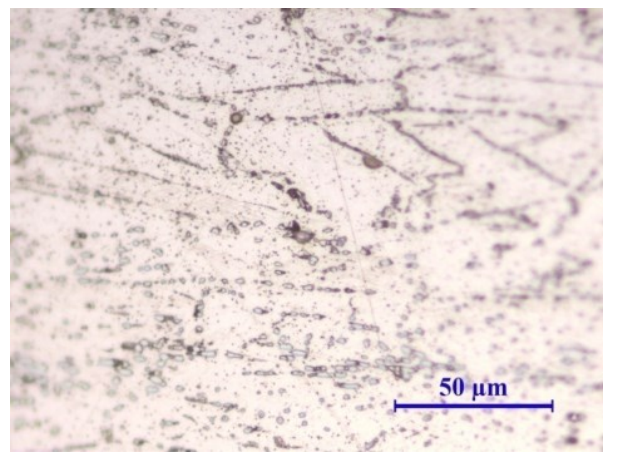

Detail

Fig. 7. Microstructure of the base material - Dominial ZF - uncycled

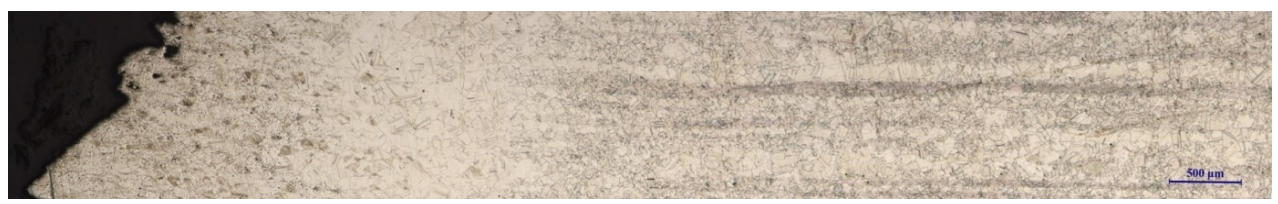

Fig. 8. Microstructure in proximity of the fracture - Dominial ZF 2 - after 50 cycles

Here, it is possible to mark the failure of the Dominial ZF 2 steel as ductile with the different size of the dimples on the edge of the sample and in its core (Fig. 9). 


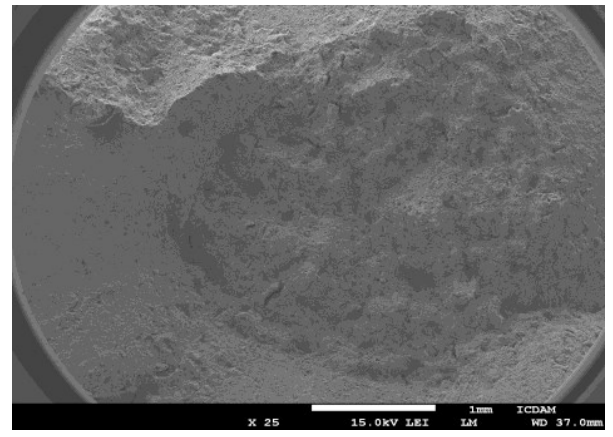

Overview

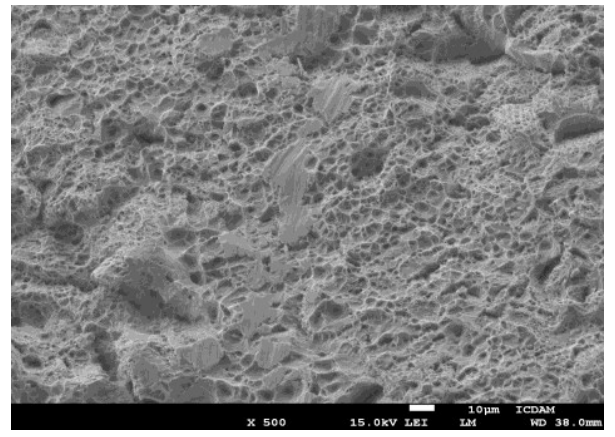

Detail

Fig. 9. Fracture surface - Dominial ZF 2 - after 50 cycles

As can be seen on the figures above the evaluated materials are typical by their heterogeneous microstructure, with which the stress - strain states manifesting in the final character of the fracture surfaces corresponded. Due to the fact that the microscopic and fractographic examination of the structures reveal different mechanisms of the failure (ductile, mixed and fragile), it is possible to attribute a strong influence of occurrence of intermediary phases to the crack initiation occurrences in the evaluated steels.

\section{Conclusions}

Based on the morphological changes of the fracture surfaces, it is possible to state that both the temperature fatigue and the creep occur during the process. In operating conditions, this is a thermo-mechanical fatigue leading to a failure of metallic material. That is why the initial structure, micro-purity, distribution and morphology of the intermetallic phases are important. This will be reflected in the fact that each micro-area will have different thermal expansion and conductivity leading to uneven strain states in the microstructure. The number of heat load cycles that the material will withstand without failing characterizes the resistance of the given material to the failure. Simulation has shown that the DOMINIAL ZF2 has always sustained the highest number of cycles until failing.

Based on these findings, it can be stated that the evaluated steels, which are supposed to replace the materials currently used, will be very sensitive to temperature changes. There is a risk of uncontrollable processes in materials initiated by thermal-mechanical load. This will further lead to a greater reduction of the service life of components made of this material. That is the reason why Toolox 33 and 44 steels are not recommended for the production of glass molds.

This work was supported by the Slovak Grant Agency VEGA 1/0649/17, VEGA 1/0589/17, KEGA 007 TnUAD-4/2017, and resulted from the project "Center for quality testing and diagnostics of materials", ITMS code 26210120046 relating to the Operational Program Research and Development funded from European Fund of Regional Development.

This work was also supported by the Ministry of Education, Youth and Sport of the Czech Republic, program NPU1, project No. LO1207.

\section{References}

1. J. Koutský, F. Jandoš, V. Karel, Lomy ocelových částí. (Praha SNTL, 1976) 
2. I. F. C. Smith, The behaviour of short fatigue cracks. Eds. K. J. Miller, E. R. de los Rios, 1-77, ISBN 981-02-4180-1, (MEP, London, 1986)

3. J. Polák, Cyklická plasticita a nizkocyklová únavová odolnost' kovových materiálov. (ČSAV Praha, 136 p., 1986)

4. D. Hull, Fractography. (University Press, Cambridge, 378 p., 1999)

5. Data Sheet 605en Toolox 33. http://www.damatech.com [online, cit. 2017-07-30] (2015)

6. Product sheet: Toolox ${ }^{\circledR} 44,450 \mathrm{HBW}$ ( 45 HRC) with ESR properties. https://eng.stahlnetz.de [online, cit. 2017-07-30] 